\title{
The Challenge of Contextualising the Scholarship of Teaching and Learning
}

\section{ABSTRACT}

Much of the literature in the field of the Scholarship of Teaching and Learning (SoTL) discusses the need for SoTL and how critical inquiry can support teaching and learning. This article supports much that has been said before but further suggests that, in order for SoTL to fulfil its ambitions, practitioner-researchers should consider the way that their environment shapes them. It is suggested that, by reflecting on their specific context, practitioner-researchers can engage in a practice that is more suited to supporting those who learn within such a context. Further, it is recommended that sharing such reflections through published work could help secure the development of such practice within and across the academy.

\section{KEYWORDS}

context, environment, space, practice and perspective.

\section{INTRODUCTION}

Critical inquiry lies at the heart of the Scholarship of Teaching and Learning (SoTL), and it is through this inquiry that scholars seek to discover how teaching can best support learning. Much of the literature in this field has focused on what SoTL might be (Boyer, 1990; Trigwell, Benjamin \& Prosser, 2000) and why academics should scrutinise their practice (Atkinson, 2001; Hutchings \& Schulman, 1999). Some have offered broad guidelines in order to facilitate the development of scholarship (Murray, 2008), and others have offered specific criteria to be used to analyse practice (Akerlind, 2007). In all, the discussion has focused on what SoTL is, why we should have SoTL, and how SoTL might support teaching and learning, but there has been little discussion regarding the context in which SoTL exists-the where of SoTL.

The processes of teaching and learning are imbued with contextuality (Samuelowicz \& Bain, 2001). Parlett (1991) highlights the interconnection of human beings and their context, suggesting that situations need to be understood holistically, recognising the "indivisibility of people and their surroundings" (p. 2). Yet, whilst there is evidence to suggest that the teaching process is influenced by context (Johnson, 2002; Stes, Gijbels \& Van Petegem, 2008;), Gordon et al., (2011) report that there is great scope for the enhancement of the research process through a developed awareness of this context. If research should "conform to the obligations of the professional context" (Stenhouse, 
1983; p.20), then it is also true that research into SoTL should pay close scrutiny to the "obligations" of the environmental context.

Research on SoTL and context has tended to focus on specific aspects of context: the university campus (Kreber, 2002), the political climate (Frederiksen \& Beck 2010), or the online environment (Macdonald \& Black, 2010). However, instead of looking at SoTL in relation to specific contextual features, we might take a step back and contemplate context in an ontological sense, looking at what it means to find oneself in a certain space and how that space might affect our behaviour within it. Here the importance of contextualised scholarship is stressed, and it is argued that to ignore the space in which scholarship occurs is to leave SoTL at odds with its emancipatory aims.

\section{CONTEXTUAL INFLUENCE}

There is a "general principle of the shaping of actual experience by environing principles" (Dewey, 1997, p. 40), which suggests that the places in which we work, live, research, and play are likely to have an effect upon us — a shaping effect. Foucault (1986) tells us of the recognisable qualities of spaces and how these have an impact upon our experiences within them. Relating this "shaping" concept to SoTL means that practitionerresearchers should consider their work within a contextual framework rather than merely attempting to examine the teaching-learning nexus as an abstract construction. All teaching and learning takes place within a space that is more than just physical; therefore, the teaching and learning context - the wider societal context, and the cultural, ethical, and philosophical climate - are inseparable from our lived experiences.

Places have a vibe or ethos such that the qualities of a nursery are very different from the qualities of a university. The same is also true at the geographic and political level where working in one specific region or country is very different from working in another. Such spaces have a bearing on our perceptions of teaching and learning and to be scholarly about teaching and learning should mean embracing the individual qualities of the space that our research takes place in.

Adopting such a position means that the "truth" our research seeks to find is a construction of our interaction with the environment, and that there can be no fixed and constant answers to educational problems. There are two main considerations here: firstly, that the truth of research established within one environment might not be easily transferable to another environment. Secondly, what individuals report in one environment might differ from what they report in another. Neither of these points necessarily reduces the validity of data and it may be that embracing a contextualised perspective allows for a more individualised and authentic understanding of individuals within certain spaces. In this conception, SoTL is not about seeking universal answers that might be generalised but about searching for individual answers that are unique and that might help create the thick description (Geertz, 1973) of a particular research context.

As practitioner-researchers examine the world in which they practice, they take a hermeneutic approach. Each scholar will 'read' their data from their own perspective and within their own context-interpreting their results in a "social" manner by looking at how the interrelationships of teaching and learning play against each other and against the space in which teaching and learning take place. Developing individualised contextorientated data on teaching and learning will allow scholars to make recommendations in response to their specific situation and that are attuned to the needs of those in that 
environment. To attempt to develop comprehensive theories and methodologies from specific data would be naïve and would not only ignore the situational aspects of education but would ignore the individuality of teaching and learning.

Further, in adopting contextualised SoTL, practitioner-researchers are not only able to tell the story of their particular situation, they can also draw their findings together and when the work of many scholars comes together a type of Venn diagram can be createdin the overlapping areas we might see the things that are common to many areas of practice. Here we can clearly see how a community of like-minded but differently-situated scholars can pull together their findings and construct something that is bigger than the sum of the parts. Such a peer-built and peer-reviewed overview of SoTL in relation to context would then allow subsequent researchers in this field to work from an established understanding of common themes, details and differences. In this regard, research becomes a collegiate construction and works to build community understanding through shared scholarship. This Venn diagram metaphor might be thought of as a meta-analysis of studies on contextualised scholarship, but in order for such a study to take place, we must first of all engage with developing published work in this field.

\section{RECOMMENDATION}

Scholarship needs to take an individual and situated approach: focusing on specific cases then collating findings in order to find points of intersection with colleagues' work. Instead of attempting to limit situational bias, there needs to be a harmonisation of space and scholarship. Here it is recommended that scholars analyse their teaching in relation to their context and consider how the space that they inhabit might affect their practice within it and might likewise affect the learning that takes place there. Bleek (1979) suggests that problems of bias are less likely when there are few differences between the researcher and the researched. In embracing the scholarship of teaching and learning at the contextual level, we can reduce the asymmetrical relationship between the researcher and the researched by considering that all those within one context are influenced by similar contextual factors.

In reflecting upon their specific context, practitioner-researchers should consider, inter alia, their geographical situation; the point in history that they inhabit; the local politics; the ethos of the establishment in which they work; the demands of the community in which they are located; their institution's philosophies on teaching and learning; their own pedagogical assumptions; and their perceptions of the current zeitgeist.

Those involved in SoTL seek to improve the teaching and learning experience. Such a goal is emancipatory and practical. Without building a body of published work, these goals may need to be problematized anew by each scholar; therefore, it is recommended that scholars don't merely work to improve their local situation but actively "collect and present rigorous evidence" (Brew \& Ginns, 2008, p. 535). Understanding one's own perspective and paradigm through understanding one's own situation could help secure the development of a practice that is situationally valid and more suited to supporting those who learn within such a place. And sharing such understanding through published work could help secure the development of such practice within and across the academy.

Erik Blair is a Research Fellow in the Scholarship of Teaching and Learning at the University of the West Indies, Trinidad and Tobago. 


\section{REFERENCES}

Akerlind, G.S. (2007). Constraints on academics' potential for developing as a teacher. Studies in Higher Education, 32(1), 21-37.

Atkinson, M.P. (2001). The Scholarship of Teaching and Learning: Reconceptualising scholarship and transforming the academy. Social Forces, 79(4), 1217-1229.

Bleek, W. (1979). Envy and inequality in fieldwork: An Example from Ghana. Human Organization, 38(2), 200-205.

Brew, A. \& Ginns, P. (2008). The relationship between engagement in the scholarship of teaching and learning and students' course expectations. Assessment \& Evaluation in Higher Education, 33(5), 535-545.

Boyer, E. (1990). Scholarship reconsidered: Priorities for the professoriate. Carnegie Foundation for the Advancement of Teaching. University of Princeton: New Jersey.

Dewey, J. (1997). Experience and education. The Kappa Delta Pi Lecture Series: Touchstone.

Foucault, M. translated J. Miskowiec. (1986). Of other spaces. Diacritics, 16(1), 22-27.

Frederickson, L.F. \& Beck, S. (2010). Caught in the crossfire: Education research in context. International Journal of Research and Method in Education, 33(2), 135-149.

Geertz, C. (1973). Thick Description: Towards an interpretive theory of culture, in C. Geertz (Ed.) The investigation of cultures. New York: Basic Books.

Gordon, J.B., Levine, R.J., Mazure, C.M., Rubin, P.E., Schaller, B.R. \& Young, J.L. (2011). Social contexts influence ethical considerations of research. The American Journal of Bioethics, $11(5), 24-30$.

Hutchings, P. \& Schulman, L. (1999). The scholarship of teaching: New elaborations, new developments. Change: The Magazine of Higher Learning, 31(5) 10-15.

Johnson, B. E. (2002). Contextual teaching and learning: Why it is and why it is here to stay. California: Sage Publications Ltd.

Kreber, C. (2002). Controversy and consensus on the scholarship of teaching. Studies in Higher Education, 27(2), 151-167.

Macdonald, J. \& Black, A. (2010). Disciplinary knowledge in distance education: Testing a new methodology for teaching enhancement in History. Arts and Humanities in Higher Education, 9(1), 69-86.

Murray, R. (2008). The Scholarship of Teaching and Learning in Higher Education: Helping students learn. Maidenhead: Society for Research into Higher Education and Open University Press.

Parlett, M. (1991). Reflections on Field Theory. The British Gestalt Journal, 1, 68-91.

Samuelowicz, K. \& Bain, J. (2001). Revisiting academics' beliefs about teaching and learning. Higher Education, 41(3), 299-325.

Stenhouse, L. (1983). Research as a basis for teaching. Inaugural lecture from University of East Anglia, in L. Stenhouse (Ed.) Authority, education and emancipation. London: Heinemann.

Stes, A., Gijbels, D., \& Van Petegem, P. (2008) Student-focused approaches to teaching in relation to context and teacher characteristics. Higher Education, 55(3), 255-267.

Trigwell, K.E., Benjamin, M.J. \& Prosser, M. (2000). Scholarship of teaching: A model. Higher Education Research and Development, 19(2), 155-168. 